\title{
Evaluation of the Use of Microwave Energy on The Reduction of Iron Ore and Steelmaking Mill Scale Composite Self-Reducing Mixtures
}

\author{
Leonardo Martins da Silva ${ }^{a}$ * (1), Tamara Fernandes Eugênio ${ }^{b}$, Giulio Antunes de Medeiros ${ }^{a}$, \\ Ronaldo Gomes de Castro Medeirosc, Patrícia Guimarães Monteiro de Freitasc, \\ José Adilson de Castro ${ }^{a}$ (D)
}
${ }^{a}$ Universidade Federal Fluminense, Av. dos Trabalhadores, 420, Vila Sta. Cecília, 27255-125, Volta Redonda, RJ, Brasil.
${ }^{b}$ Colégio Estadual Piaui, Rua Roterdam, 33, Ponte Alta, 27267-370, Volta Redonda, RJ, Brasil. 'Pontifícia Universidade Católica do Rio de Janeiro, Rua Marquês de São Vicente, 225, 22541-041, Gavea, RJ, Brasil.

Received: September 4, 2021; Revised: November 06, 2021; Accepted: November 29, 2021

\begin{abstract}
With the growing industrialization, there is a constant increase in the world demand for steel, causing an increase on extraction of low-grade iron ores, which bear high levels of impurities. A feasible alternative is the use of residues from steel rolling processes (steelmaking mill scale) generated in the steel industry, which are composed of iron oxides consisting mainly of wustite $(\mathrm{FeO})$, hematite $\left(\mathrm{Fe}_{2} \mathrm{O}_{3}\right)$ and magnetite $\left(\mathrm{Fe}_{3} \mathrm{O}_{4}\right)$. In line with the recycling of wastes, the application of heating by microwave energy in ironmaking processes consists in a promising new method developed in recent decades and is considered a cleaner technique. Therefore, this study aims to evaluate the self-reduction of mixtures composed of iron ore and steelmaking mill scale as iron source, together with coke fines as carbon source, heated using microwave energy. Through the rotational central composite design technique, it was possible to evaluate the best conditions for the use of steelmaking scale residue as well as the effect of the applied microwave energy power. The results indicated that the developed process has relevant utility with up to $41.48 \%$ of reduction obtained. The outcomes contribute to a better understanding of iron recovery from steelmaking residues in reduction processes using microwave energy for heating, providing significant insight for the development of new clean technologies.
\end{abstract}

Keywords: Steelmaking mill scale, Microwave, Self-reduction.

\section{Introduction}

An integrated steel mill can generate 500 to $700 \mathrm{~kg}$ of waste per ton of steel produced. Such residues can vary in composition and are generally recycled during the process itself, undergoing various types of treatment, so that they can be left in contact with the soil in a safe manner, to meet environmental regulatory standards. The impacts on the environment during the steelmaking process happen in the various stages of the process, from the transport, handling and preparation of the raw materials, through its transformation into final products, and the destination given to the various residues that result from these stages of production.

Therefore, pollution caused by steelmaking processes can be harmful to the air, water and soil. Air pollution occurs in the processing of ore (sintering), in the coke oven, in the blast furnace and, to a lesser extent, in the areas of manufacture of semi-finished products, due to the fuels and the process of burning in the furnaces. The pollutants emitted are in the form of small particles (dust) and in the form of gases, such as nitrogen oxide, sulfur oxide and carbon monoxide and dioxide. The main solid residues from the steelmaking process

*e-mail: leonardouffsilva@gmail.com are basically classified into slag, powders and sludge from blast furnaces, in addition to scale from integrated steel mills.

The simple disposal of such residues can be considered a great waste, since these materials have a high economic value. Data from the Brazil Steel Institute pointed to the fact that, in 2003, the steel industry produced 13.5 million tons of wastes, with an average of $435 \mathrm{~kg}$ of residues per ton of steel produced. The increase in income generated through the recycling of these materials, has led companies to a new policy on the issue of environmental management. Thus, the reuse of residues from the steelmaking process, whether they are gaseous, liquid or solid, in addition to a concern for meeting the requirements of legislation that protects the environment, is also an economic issue.

An example is the residue called steelmaking mill scale, being a co-product from the oxidation of steel plates surface when subjected to a thermal gradient, to the corrosive atmosphere or to the simple action of time. In the steel industry, it basically comes from unit operations of continuous casting and rolling, whose average generation can easily exceed 1000 tons/month in integrated plants. Such residues are iron oxides consisting mainly of wustite $(\mathrm{FeO})$, 
hematite $\left(\mathrm{Fe}_{2} \mathrm{O}_{3}\right)$ and magnetite $\left(\mathrm{Fe}_{3} \mathrm{O}_{4}\right)$, which the disposal in waste yards must be carefully carried out, following the relevant environmental standards, since they can be classified as hazardous wastes (CLASS I, NBR 10004: 2004). With the reuse of this residue, it is possible to obtain an average composition of $63.8 \% \mathrm{FeO}, 3.4 \% \mathrm{Fe}_{2} \mathrm{O}_{3}$ and $32.0 \% \mathrm{Fe}_{3} \mathrm{O}_{4}$, being extremely useful for ironmaking processes during steel production.

Still regarding the environmental impact, it is well-known that iron ore is the most extracted metallic mineral resource from the Earth's crust and is the main raw material used in the steel industry. The demand for iron ore is increasing, and there is a need to enable deposits that, despite having a high iron content, also contain levels of impurities above market specifications (mainly phosphorus). According to the Management and Strategic Studies Center in its publication entitled "Steelmaking in Brazil 2010-2015", there is an expectation that mined ore may have increasingly levels of phosphorus and alumina, which further supports the importance of the recycling of iron-rich wastes such as the steelmaking mill scale.

In line with the recycling of wastes, the application of heating by microwave energy in ironmaking processes consists in a promising new method developed in recent decades and is considered a clean technology. Microwave energy is a non-ionizing electromagnetic radiation with frequencies in the range $0.3-300 \mathrm{GHz}$, although the $2.45 \mathrm{GHz}$ frequency being commonly used in industrial applications. The concept of microwave heating technology was firstly proposed in the mid-1960s ${ }^{1}$. In the middle and late 1980 s, microwave heating technology was introduced into the fast preparation of materials and was used as an alternative heating method for the preparation of powder metal ${ }^{2}$. After the 1990s, the technology has developed rapidly in the fields of mineral processing, polymer, nano-organic synthesis and the preparation of special materials. Microwave energy is mainly different from conventional heating because it penetrates deeply into the volume and offers non-contact fast heating that can be applied to many different processes. Microwave heating technology has become a valuable technique for quickly preparing high-performance new materials and modifying conventional materials, based on the special energy transfer and conversion mechanism, as well as rapid heating and selective heating characteristics ${ }^{3-6}$.

Many works have reported on the heating properties of microwave energy for various materials and applicability to materials science and engineering. Guo et al. ${ }^{7}$ explored the microwave heating characteristics of fused $\mathrm{ZrO}_{2}$. They reported that fused $\mathrm{ZrO}_{2}$ was heated to $1475^{\circ} \mathrm{C}$ within $4 \mathrm{~min}$. The finding denotes the feasibility of applying microwave heating on $\mathrm{ZrO}_{2}$ ceramics preparation.

Nightingale et al. ${ }^{8}$ investigated the microstructure change of $\mathrm{Y}_{2} \mathrm{O}_{3}$-doped $\mathrm{ZrO}_{2}$ ceramics. They highlighted that the microwave sintered sample had more dense microstructures compared to conventionally heated samples. A comparison between roasting by microwave energy and conventional roasting was presented by Rath et al. ${ }^{9}$ who found that the recovery levels obtained using both routes are almost the same, while microwave roasting offers the advantage of minimal formation of unwanted products such as wustite and fayalite. Ye at al. conducted microwave carbothermal reduction experiments of low-grade pyrolusite and obtained a reduction degree of $97.2 \%$ under shorter reduction time and lower processing temperature than that by traditional heating. According to Yeqing et al. ${ }^{10}$, by replacing conventional heating with microwave heating could effectively enhance the product yield of PSZ ceramic with advantages including strong penetration, non-ionization and green energy-saving. The unique heating mechanism of microwave heating promotes an effective reaction area and an increased reaction rate, further to result in the formation of a microstructure with small particle size and uniform distribution, which in turn improves the quality and performance of the products.

Therefore, this work proposes the evaluation of the reuse of steelmaking mill scale as a raw material to ironmaking processes, to be applied together with iron ore as iron source, and coke as carbon source in self-reducing mixtures, with microwave energy used as heating source. For this purpose, a statistical analysis was designed to quantify the influence of the experimental parameters, which include mass of steelmaking mill scale, microwave power applied and residence time of the mixture inside the oven.

\section{Materials and Methods}

\subsection{Origin and preparation of the sample.}

The iron ore used in this work originated in the northern and southeastern regions of Brazil. For the heating process of the samples, a microwave oven was used, applying several different power levels. In each test, a mass value of residue was used. Figure 1 shows the schematic flowchart used for sample preparation and processing for evaluating the reuse route for steel residues.

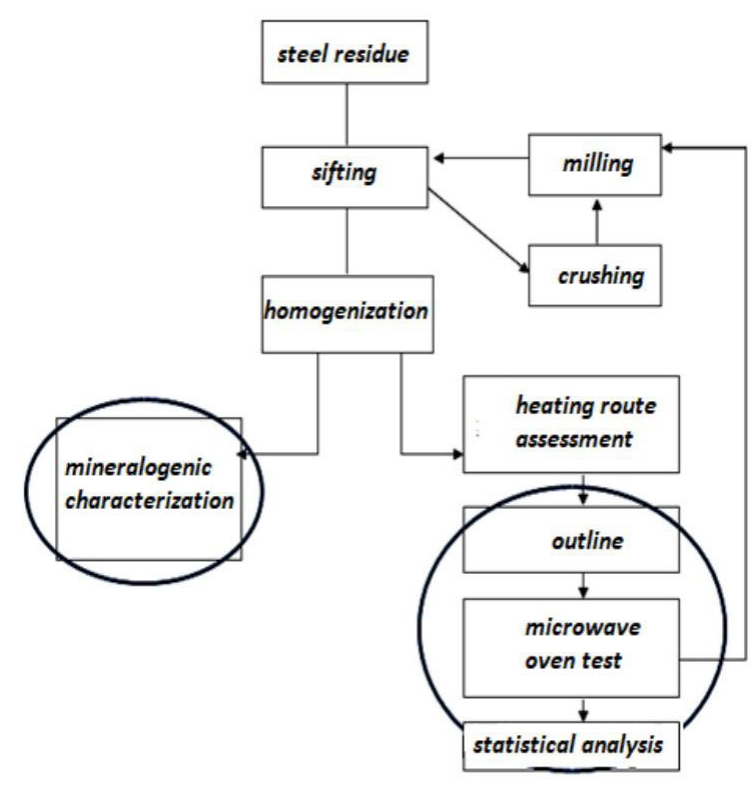

Figure 1. General flowchart for evaluating the reuse route for steel residues. 


\subsection{Characterization of raw materials}

Homogeneous self-reducing mixtures were produced from iron ore fines and coke and then mixed with steelmaking mill scale residue. The samples were analyzed using X-ray diffraction (equipment model D4 Endeavor, Bruker) and diffraction patterns were refined using the Rietveld method to identify the phases and chemical species that constitute them. The X-ray diffractometry technique using the Ritveld method is based on the simulation of an entire diffractometric profile based on structural parameters of the component phases, allowing quantitative information on the mineral phases to be extracted from the diffractograms. The Rietveld method takes into account the superposition of the peaks of all the phases present and the contributions of the background noise. Chemical analysis for coke was carried out by proximate analysis following the ASTM D3172-13. The results can be seen in Tables 1 and 2.

Hematite, Quartz and Goethite were the main phases identified through the X-ray diffraction method for iron ore, where the absence of apatitic and aluminum-silicate compounds was observed.

\subsection{Experimental procedures and statistical analyzes of the reduction of mixtures of iron ore, coke and steelmaking mill scale.}

A conventional microwave reactor with a power of $700 \mathrm{~W}$ emitting microwave radiation with a frequency of $2450 \mathrm{MHz}$ was used to treat the self-reducing mixtures. In the conventional microwave reactor, microwaves are generated through an equipment called magnetron, whose output is located in the upper right corner of the equipment. Therefore, the sample was placed in the lower left part of the equipment, where it was observed to be the place where there is a higher incidence of microwave radiation. The interior of the reactor had dimensions of $260 \mathrm{~mm}$ (height), $460 \mathrm{~mm}$ (width) and $320.3 \mathrm{~mm}$ (length). A schematic is presented in Figure 2.

Table 1. Mineralogical composition of the iron ore sample ( $\%$ by mass fraction).

\begin{tabular}{ccc}
\hline Mineral & Chemical Formula & \%Weight \\
\hline Hematite & $\left(\mathrm{Fe}_{2} \mathrm{O}_{3}\right)$ & 82.0 \\
\hline Kaolinite & {$\left[\mathrm{Al}_{2} \mathrm{Si}_{2} \mathrm{O}_{5}(\mathrm{OH})_{4} \cdot\right]$} & 1.8 \\
\hline Quartz & $\left(\mathrm{SiO}_{2}\right)$ & 9.5 \\
\hline Gibbsite & {$\left[\mathrm{Al}(\mathrm{OH})_{3}\right]$} & 0.3 \\
\hline Goethite & {$[\mathrm{FeO}(\mathrm{OH})]$} & 3.7 \\
\hline Magnetite & $\left(\mathrm{Fe}_{3} \mathrm{O}_{4}\right)$ & 0.9 \\
\hline Maghemite & $\left(\mathrm{Fe}_{2} \mathrm{O}_{3}, \gamma-\mathrm{Fe}_{2} \mathrm{O}_{3}\right)$ & 1.8
\end{tabular}

Table 2. Composition of the coke sample ( $\%$ by mass fraction).

\begin{tabular}{cc}
\hline Component & Mass Fraction (\%) \\
\hline Fixed Carbon & 88.44 \\
\hline Volatile Matter & 0.50 \\
\hline Ashes & 11.06 \\
\hline
\end{tabular}

The samples were inserted one at a time into the reactor using a ceramic crucible, thermally insulated with a refractory brick and were treated with different levels of time and microwave power under air atmosphere. When the sample residence time in the reactor was reached, the treatment was interrupted and the sample was then weighted.

For the evaluation of the process of carbothermal reduction of iron oxides using microwave energy, the central rotational composite design (DCCR) was used, by which it was possible to evaluate the influence of the independent variables time, power and percentage of residue in the degree of reduction of the sample inside the microwave oven. For this purpose, different samples were used, composed of fines of iron ore and coke with an average particle size of $53 \mu \mathrm{m}$, mixed with steelmaking mill scale.

Experimental planning based on statistical principles allows the maximum amount of useful information to be extracted from the system under study, making a minimum number of experiments and constituting one among several techniques available to scientists and engineers to improve systems, processes and products. These techniques are powerful tools, with which several specific objectives can be achieved.

Table 3 shows the values used in the factorial design within each experimental coefficient interval and also within the levels $(-1.68 ;+1.68)$, and outside these levels.

The values shown in Table 3 were stipulated considering the average between the upper and lower axial values.

With the degree of final experimental reduction unknown, the degree of reduction of the samples was then determined based on the dissociation of oxygen bound to Iron atoms, using Equation 1, as follows:

$$
R=\frac{4}{7 W_{O}}\left(f_{t}-f_{v o l}\right) W
$$

Where $W_{O}$ is the mass of oxygen present in the iron oxides contained in the ore, $f_{t}$ is the percentage loss of total mass of the sample after the test and $f_{v o l}$ is the mass of volatile materials lost during the test time considered. To estimate the mass of volatiles lost during the tests, initially thermogravimetric tests were performed for the coke fines separately, covering all points of the experimental design and additional points, in order to obtain a profile of degree of reduction as a function of time reaction and microwave power.

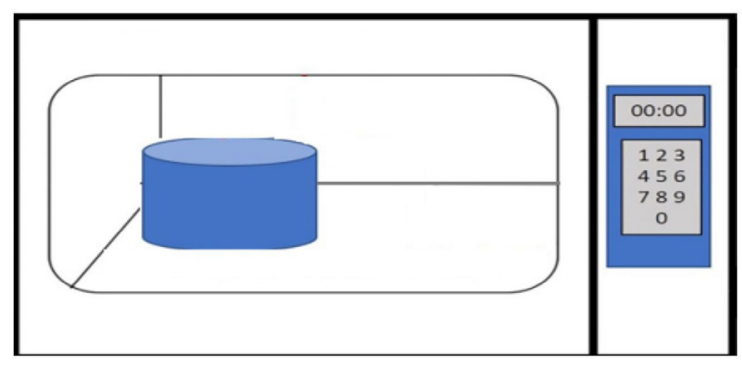

Figure 2. Microwave emitter reactor with sample location. 


\section{Results and Discussion}

\subsection{Degree of reduction of iron ore particles and steelmaking mill scale using microwave energy.}

Table 4 lists the interactions between independent properties to be analyzed in this study in the form of an experimental design composed of 15 tests as well as the resultant degrees of reduction obtained for each experiment.

Figure 3 shows the profile of the degree of reduction of the mixture of coke, iron ore and scale according to the scale mass, power and contact time of the mixture with microwave energy.

It was observed that the test with the greatest reduction was the one with 6 minutes of contact with microwave energy, $16 \mathrm{~g}$ of steelmaking mill scale and $350 \mathrm{~W}$ of power applied.

Haque et al. ${ }^{11}$ presented a review on the application of microwaves in the field of mineral engineering, where he stated that the rapid heating of ore particles that occurred through the application of microwave energy in ores with a transparent matrix generates thermal stress of sufficient magnitude to create micro-cracks along the grain boundaries of minerals. This type of micro-cracks has a high potential to improve the efficiency of iron ore reduction processes.

Figure 4 presents a micrograph of iron ore particles exhibiting micro-cracks after the application of microwave energy.

According to Ohmran et al. ${ }^{13}$, microwave pretreatment generates intergranular fractures between gangue (fluorapatite and chamosite) and oolitic hematite. These intergranular fractures improve the release of iron ore. According to

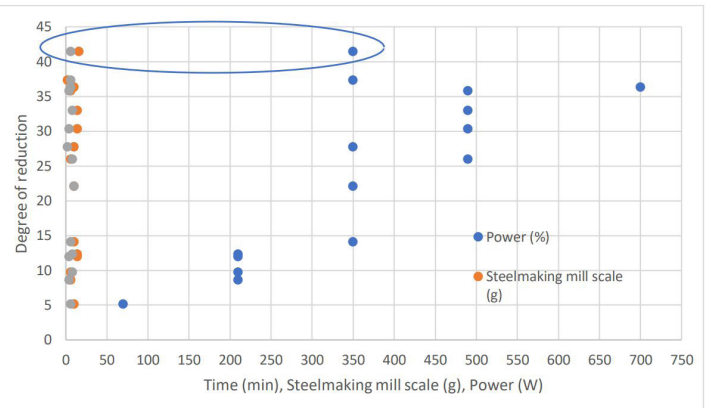

Figure 3. Degree of reduction of the mixture of coke, iron ore and steel mill scale as a function of the scale mass, power and time of contact with microwave energy.

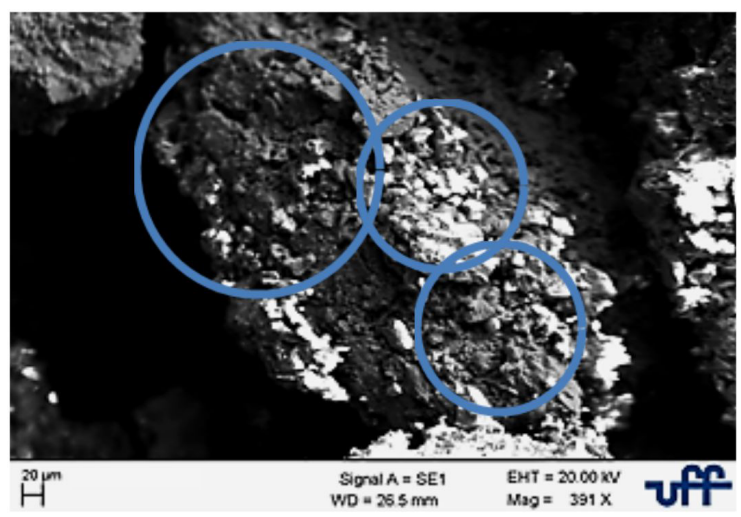

Figure 4. Micrograph of iron ore particles after application of microwave energy. (appud Silva et al) ${ }^{12}$

Table 3. Variables and levels used in factorial planning.

\begin{tabular}{cccccc}
\hline Variables & $\mathbf{- 1 , 6 8}$ & $\mathbf{- 1}$ & $\mathbf{0}$ & $\mathbf{+ 1}$ & $\mathbf{+ 1 , 6 8}$ \\
\hline Time (min) & 2 & 4 & 6 & 8 & 10 \\
\hline Steelmaking Mill Scale (g) & 2 & 6 & 10 & 14 & 16 \\
\hline Power (Watts) & 70 & 210 & 350 & 490 & 700 \\
\hline
\end{tabular}

Table 4. Specific description of the tests performed and the results of the reduction tests obtained through factorial design of experiments using the central rotational composite design (DCCR).

\begin{tabular}{ccccc}
\hline Test & Time & $\begin{array}{c}\text { Steelmaking Mill Scale } \\
\mathbf{( g )}\end{array}$ & Power (Watts) & Reduction (\%) \\
\hline 1 & 4 & 6 & 210 & 8,66 \\
\hline 2 & 8 & 6 & 210 & 9,74 \\
\hline 3 & 4 & 14 & 210 & 11,98 \\
\hline 4 & 8 & 14 & 210 & 12,35 \\
\hline 5 & 4 & 6 & 490 & 35,84 \\
\hline 6 & 8 & 6 & 490 & 25,99 \\
\hline 7 & 4 & 14 & 30,35 \\
\hline 8 & 8 & 14 & 33,01 \\
\hline 9 & 2 & 10 & 490 & 27,75 \\
\hline 10 & 10 & 10 & 350 & 22,14 \\
\hline 11 & 6 & 2 & 350 & 37,38 \\
\hline 12 & 6 & 16 & 350 & 41,48 \\
\hline 13 & 6 & 10 & 350 & 5,2 \\
\hline 14 & 6 & 10 & $\mathbf{7 0 0}$ & 36,33 \\
\hline 15 & 6 & 10 & 350 & 14,11 \\
\hline
\end{tabular}


Jones et al. ${ }^{14}$, fractures in the ore particles occur across the grain boundary between absorbent and transparent species. Thus, such fractures can generate an increase in the release of iron oxide from iron ore particles, thus improving the rate of iron oxides reduction in iron ore particles.

In line with the previous statement, Yu and $\mathrm{Qi}{ }^{15}$ studied the mechanism of reduction of ore fines containing oolitic hematite. The temperature for the reduction experiments was maintained at $800-900^{\circ} \mathrm{C}$. They concluded that the $\mathrm{CO}$ gas diffuses and is adsorbed onto the surface of the hematite particles, producing magnetite and carbon dioxide. It was established that the $\mathrm{Fe}^{2+}$ ion and electrons are generated in the outer layer and enter the $\mathrm{Fe}_{2} \mathrm{O}_{3}$ matrix through empty positions, and thus, the magnetite is generated through the construction of a network. A similar reaction occurs until the inner layer of hematite turns into magnetite. Magnetite formation was observed in around 30-60s of heating.

\subsection{Degree of reduction of the mixtures as a function of the variation in steelmaking mill scale mass and time of contact with microwave energy.}

Figure 5 shows the contour plot of the degree of reduction of the self-reducing mixtures as a function of the variation in steelmaking mill scale mass and time of contact with microwave energy.

It was possible to observe that higher values of the degree of reduction occur for intermediate times and higher amounts of steelmaking mill scale. It was also possible to observe that for short reaction times and small values of steelmaking mill scale, high values of degree of reduction occur. This fact can be confirmed by Hake et al. ${ }^{11}$ who stated that the rapid heating of the ore particles occurs through the application of microwave energy in ores with a transparent matrix where it generates thermal stress of sufficient magnitude to create microcracks along the grain boundaries of the minerals.

Hayashi et al. ${ }^{16}$ concluded that the hematite ore is heated with greater difficulty by microwaves. It was also found that the rate of reduction of hematite powder with graphite as a reductant is faster when compared to magnetite powders. Kashimura et al. ${ }^{17}$ used microwave energy for the carbothermal reduction of magnetite. They found that the magnetic field produced by microwaves generates a temperature that quickly heats the center of the sample, however the mixed mode E-H resulted in higher temperatures. In addition, the microwave magnetic field resulted in lower $\mathrm{FeO}$ content and higher $\alpha$-Fe compared to the mixed E-H mode. Thus, it was clear that the collective effect of the microwave magnetic field and thermal energy increases the deoxidation of iron ore and the microwaves act as a catalyst at high temperatures.

\subsection{Degree of reduction of the mixtures as a function of the variation in power and time of contact with microwave energy.}

Figure 6 shows the contour plot of the degree of reduction of the self-reducing mixtures as a function of the variation of the applied power and the time of contact with the microwave energy.

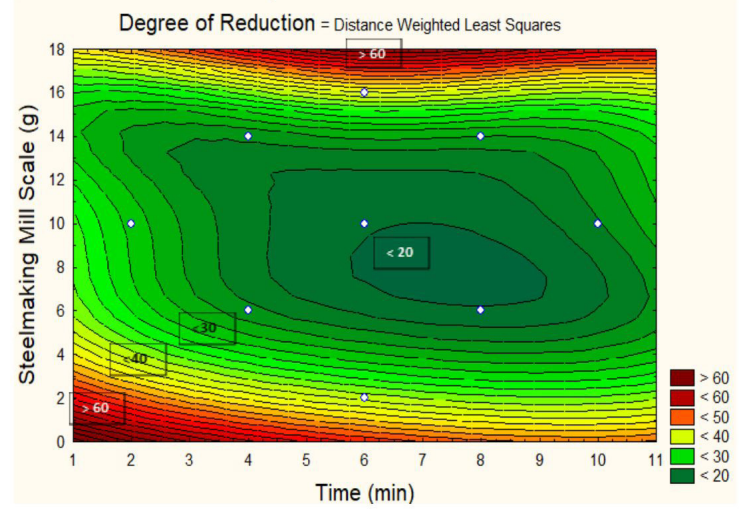

Figure 5. Contour plot of the degree of reduction as a function of the mass variation of the steelmaking mill scale and contact time of the mixture of ore, coke and scale with microwave energy.

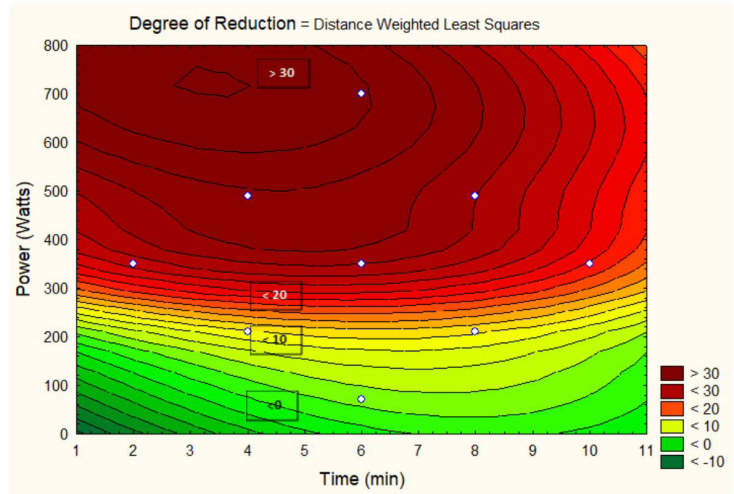

Figure 6. Contour plot of the degree of reduction as a function of the variation of the applied power and the contact time of the mixture of ore, coke and scale with microwave energy.

The results indicated that higher values of the degree of reduction of the self-reducing samples were obtained for high microwave power levels regardless of reaction time. In line with the increase in the degree of iron oxides reduction obtained, Agarwal et al. ${ }^{18}$ compared the red mud carbothermal reduction when applying conventional and microwave heating techniques. They found that the microwave route provided a significant improvement in the degree of iron reduction at lower levels of time and coal amount, as well as faster reduction rate, cleaner processing and savings when compared to conventional roasting.

\subsection{Degree of reduction of the mixtures as a function of the mass variation of steelmaking scale and applied microwave power.}

Figure 7 shows the profile of reduction of the self-reduction mixtures as a function of the variation in steelmaking scale mass and microwave power applied.

It can be observed that higher values of the degree of reduction for the self-reducing mixtures were obtained for higher power levels at any microwave reaction time applied to the particles. This fact is supported by Samouhos et al. 


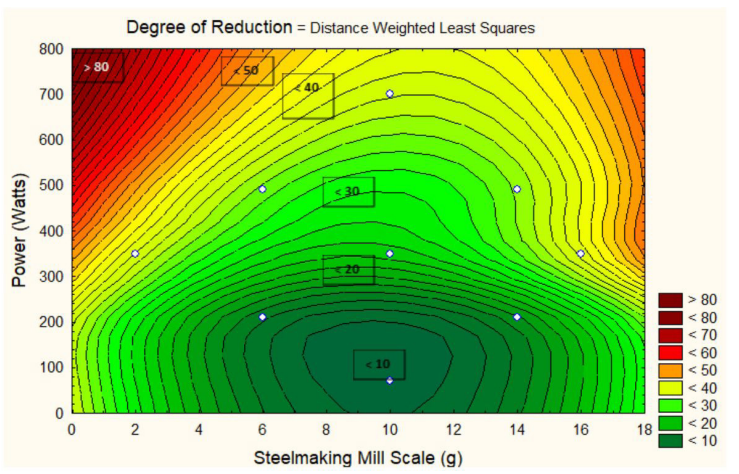

Figure 7. Contour plot of the degree of reduction as a function of the steelmaking mill scale mass variation and the time of contact of the mixture with microwave energy.

$2013^{19}$ who applied microwave energy to reduce iron from an alternative source of hematite like red mud using lignite with $30.15 \%$ wt fixed carbon as reductant. The dielectric constants were measured, and it was found that, as a result of the reduction in hematite, the imaginary permissiveness $(\varepsilon ")$ increased and, therefore, microwave absorption also increased during the process of roasting for reduction. In line with the previous statement, Yeqing et al. ${ }^{19}$ stated that the microwave heating process depends on the dielectric loss of each component of the sample. Thus, the technique can achieve the effect of selective heating. Microwaves can penetrate the material and generate heat through its whole volume, i.e., regardless of the heat conduction process, and therefore the whole material can be heated quickly. Also, the microwave will not be lost in the metal resonant cavity, which effectively reduces the energy loss and improves the energy utilization rate. Then the material properties can be improved, the internal stress caused by uneven heating can be reduced, and the cracks can be effectively avoided. Especially for the materials with poor thermal conductivity, the effect is more obvious.

According Yeqing et al. ${ }^{19}$, under the action of the microwave electromagnetic field, ceramic materials will produce a series of dielectric polarization, such as electronic polarization, atomic polarization, dipole turn polarization and interface polarization. In another study ${ }^{6}, \mathrm{Ba} 0.5 \mathrm{Sr} 0.5 \mathrm{Co} 0.8 \mathrm{Fe} 0.2 \mathrm{O}_{3}-\delta$ (BSCF) cathode layer for fuel cells was prepared by a method based on microwave heating. It was observed that the duration of microwave-based reduction is approximately $40 \%$ shorter compared to the conventional route. In accordance with the previous statement, Rayapudi et al. ${ }^{20}$ used microwave-based reduction roasting followed by magnetic roasting separation of iron ore $(32 \% \mathrm{Fe})$ and reached the considerable degree of $57.19 \% \mathrm{Fe}$ and $17.82 \%$ of iron recovery in ideal conditions, power at $540 \mathrm{~W}, 7 \%$ coal and $3 \mathrm{~min}$ of roasting time. Similarly, microwave-assisted carbothermic reduction of a jasper hematite iron ore (approx..37\% Fe) was investigated. Still, Rayapudi et al. ${ }^{20}$ showed that through a statistically optimized condition of $720 \mathrm{~W}$ power, $9 \%$ coal and $8 \mathrm{~min}$ of roasting time resulted in approximately $61.6 \% \mathrm{Fe}$ and $73.4 \%$ of iron recovery. In addition to the superior iron values, ferrite formation was observed due to the rapid melting of the coal-ore mixture under experimental conditions of $900 \mathrm{~W}$ of power, $12 \%$ of coal and $8 \mathrm{~min}$ of roasting time with a magnetic saturation of about $153 \mathrm{emu} / \mathrm{g}$. Likewise, gas-based fluidized magnetization roasting was carried out by Jianwen et al. ${ }^{21}$ using $\mathrm{CO}$ as a reducing gas and N2 gas as a fluidizing fluid to treat iron ore residues $(33.19 \% \mathrm{Fe})$. Meeting the need for additional energy application and the advantages of microwave energy application the gasbased reduction roasting was adopted by Zhao et al. ${ }^{22}$ who studied the synergistic effect of 3 gas-based reducers such as $\mathrm{CO}, \mathrm{H}_{2}$ and water-gas $\left(\mathrm{CO}+\mathrm{H}_{2}\right)$ on low-grade siderite fines. It was found that the water-gas mixture improved the magnetization roasting, reducing the activation energy of the process and, therefore, accelerating the reaction. Zhao et al. ${ }^{23}$ also revealed the ideal condition obtained from the method mentioned above, which consisted of preheating at $550^{\circ} \mathrm{C}$. Wu et al. ${ }^{24,25}$ reported the phase transformation of the iron present in the limonite ore sample by microwave treatment with the addition of alkaline lignin. The iron oxides present in the limonitic sample can be reduced to magnetic iron oxides, including $\gamma-\mathrm{Fe}_{2} \mathrm{O}_{3}$ and $\mathrm{Fe}_{3} \mathrm{O}_{4}$ in the following sequence: $\mathrm{FeOOH} / \alpha-\mathrm{Fe}_{2} \mathrm{O}_{3} \rightarrow \gamma-\mathrm{Fe}_{2} \mathrm{O}_{3} \rightarrow \mathrm{Fe}_{3} \mathrm{O}_{4}$ with the addition of alkaline lignin below $5 \%$. The study of magnetic properties using sample magnetometer vibration (VSM) described that an iron concentrate comprising $88.72 \%$ magnetic iron oxides with a maximum magnetic saturation of $41.393 \mathrm{emu} / \mathrm{g}$ is achievable by microwave treatment at a temperature of $200^{\circ} \mathrm{C}$ and a power of $600 \mathrm{~W}$ with $5 \%$ alkaline lignin for a roasting time of $30 \mathrm{~min}$. Sunil et al. ${ }^{26}$ explored the microwave reduction response of a sample of slime iron ore, containing $56.1 \% \mathrm{Fe}$ using four different types of reducers, namely coconut shell, goat dung, cow dung and coal. Among them, coconut shell was considered promising, leading to an iron concentrate of $64.3 \%$ Fe with a total recovery of $\mathrm{Fe}$ of $97 \%$. Most studies related to microwave-based reduction have dealt with a minimum amount of sample and high-grade reducers such as graphite or coal. However, Roy et al. ${ }^{27}$ made similar studies for two low-grade iron ore samples on a scale of about $500 \mathrm{~g}$ and used a low-grade coal sample as the reducer. It has been established that magnetite ores respond much better to reduction by microwave-assisted roasting compared to goethetic ore, having precisely the same iron content. They found that a mixture of goethite-rich ore with titanium-magnetite ore in a 60:40 weight ratio, when subjected to microwave energy and magnetic separation, can result in a $61.57 \%$ Fe concentrate with a recovery of Fe of $64.47 \%$. However, intensive research in big scale and the use of low-grade coals as a reducer is essential to understand the commercial viability of the microwave process.

\section{CONCLUSION}

In order to evaluate the profile of the reduction of iron oxides contained in the iron ore and steelmaking mill scale, as well as the advantages inherent to the process of heating by microwave energy, a statistical modeling was elaborated, evaluating the best conditions for the reduction of self-reducing mixtures containing coke as reducing agent. Thus, the following conclusions were drawn:

- Through the values demonstrated by the statistical evaluation it was possible to conclude that higher 
values of reduction of iron oxide contained in mixtures of iron ore, steelmaking mill scale and coke, heated by microwave energy were found for higher amounts of steelmaking mill scale and intermediary microwave power levels. The test with the greatest degree of reduction $(41.48 \%)$ was obtained with 6 minutes of contact with microwave energy, $16 \mathrm{~g}$ of steelmaking mill scale and 350 Watts of microwave energy applied.

- Through the values demonstrated by the iron reduction rate, it is possible to conclude that the fractures generated by the heating of the particles are beneficial for the reduction of the iron oxides of the particles.

- Through the values shown for the reduction of iron oxides in the iron ore particles using steel mill scale as an additional source of iron, it was possible to conclude that under the applied conditions it is beneficial to increase the steel mill scale content in the mixture of iron ore and coke using high levels of microwave power. However, a nonlinearity between the degree of reduction and the independent variables was observed, with a lower efficiency being observed for intermediary levels of steel mill scale applied.

\section{Acknowledgements}

The authors thank the funding agencies: Coordination of Improvement of Higher Education Personnel, (CAPES). Ministry of Science and Technology. They also thank the Metallurgical Engineering graduate program of the Fluminense Federal University for the scientific technical support.

\section{References}

1. Li KQ, Chen J, Peng JH, Omran M, Chen G. Efficient improvement for dissociation behavior and thermal decomposition of manganese ore by microwave calcination. J Clean Prod. 2020; 260:121074.

2. Kleebe HJ, Braue W, Schmidt H, Pezzotti G, Ziegler G. Transmission electron microscopy of microstructures in ceramic materials. $\mathrm{J}$ Eur Ceram Soc. 1996;16(3):339-51.

3. Monaco C, Prete F, Leonelli C, Esposito L, Tucci A. Microstructural study of microwave sintered zirconia for dental applications. Ceram Int. 2015;41(1):1255-61.

4. Yan DK, Zhang HA, Yi JY, Tang S. Study on preparation and microwave sintering process of ultra-fine Ti-CN matrix cermet. Hot Working Technol. 2010;39(20):73-9.

5. Halim A, Sudin I, Ali WFFW, Yasak R, Othman MA, Abdullah $\mathrm{NS}$, et al. Formation of yttria aluminium garnet by microwave sintering. Mater Sci Forum. 2020;5946:222-7.

6. Liu WY, Kou HN, Wang XF, Bi L, Zhao XS. Improving the performance of the $\mathrm{Ba} 0.5 \mathrm{Sr} 0.5 \mathrm{Co} 0.8 \mathrm{Fe} 0.2 \mathrm{O} 3-\delta$ cathode for proton-conducting SOFCs by microwave sintering. J Ceramics International. 2019;45(16):20994-8.

7. Guo SH, Chen G, Peng JH, Chen J, Mao JL, Li DB, et al. Preparation of partially stabilised zirconia from fused zirconia using sintering. J Alloys Compd. 2010;506(1):L5-7. http://dx.doi. org/10.1016/j.jallcom.2010.06.156.

8. Nightingale SA, Worner HK, Dunne DP. Microstructural development during the microwave sintering of yttria-zirconia ceramics. J Am Ceram Soc. 1997;80(2):394-400. http://dx.doi. org/10.1111/j.1151-2916.1997.tb02843.x.

9. Rath SS, Dhawan N, Rao DS, Das B, Mishra BK. Beneficiation studies of a difficult to treat iron ore using conventional and microwave roasting. Powder Technol. 2016;301:1016-24. http:// dx.doi.org/10.1016/j.powtec.2016.07.044.

10. Yeqing L, Li Q, Zheng H, Omran M, Gao L, Chen J, Chen G. Optimisation on the stability of $\mathrm{CaO}$-doped partially stabilised zirconia by microwave heating. Ceram Int. 2021;47:8067-74.

11. Haque KE, Microwave energy for mineral treatment processes: a brief review. International Journal of Mineral Processing, 1999;57(1):1-24

12. Silva LM. 2015 Avaliação da Rota Bio - termo - hidrometalúrgica para redução do teor de fósforo no minério de ferro [thesis]. Rio de Janeiro: Universidade Federal Fluminense.

13. Omran M, Fabritius T, Mattila R. Thermally assisted liberation of high phosphorus oolitic iron ore: a comparison between microwave and conventional furnaces. Powder Technol. 2015;269:7-14. http://dx.doi.org/10.1016/j.powtec.2014.08.073.

14. Jones DA, Kingman SW, Whittles DN, Lowndes IS. Understanding microwave assisted breakage. Miner Eng. 2005;18:659-69.

15. Yu Y, Qi C. Magnetizing roasting mechanism and effective ore dressing process for oolitic hematite ore. J. Wuhan Univ Technol Mater Sci Ed. 2011;26:176-81. http://dx.doi.org/10.1007/s11595011-0192-6.

16. Hayashi M, Takeda K, Kashimura K, Watanabe T, Nagata K. Carbothermic reduction of hematite powders by microwave heating. ISIJ Int. 2013;53:1125-30. http://dx.doi.org/10.2355/ isijinternational.53.1125.

17. Kashimura K, Sato M, Hotta M, Kumar Agrawal D, Nagata K, Hayashi $\mathrm{M}$, et al. Iron production from $\mathrm{Fe} 3 \mathrm{O} 4$ and graphite by applying 915MHz microwaves. Mater Sci Eng A. 2012;556:9779. http://dx.doi.org/10.1016/j.msea.2012.07.049.

18. Agrawal S, Rayapudi V, Dhawan N. Comparison of microwave and conventional carbothermal reduction of red mud for recovery of iron values. Miner Eng. 2019;132:202-10. http://dx.doi. org/10.1016/j.mineng.2018.12.012.

19. Yeqing L, Li Q, Hewen Z, Mamdouh O, Gao L, Kangqiang L, Chen G. Drying kinetics and microstructure evolution of nano-zirconia under microwave pretreatment. Ceram Int. 2021;47:22530-9.

20. Rayapudi V, Dhawan N. Up-gradation of banded iron ores for pellet grade concentrate. Mater Today Proc. 2018;5(9):17035-40. https://doi.org/10.1016/j.matpr.2018.04.109.

21. Jianwen Y, Yuexin H, Peng G, Yanjun L, Shuai Y, Wenbo L. An innovative methodology for recycling iron from magnetic pre-concentrate of an iron ore tailing. Physicochem Probl Miner Process. 2018;54(3):668-676.

22. Zhao Q, Xue J, Chen W. Mechanismof improvedmagnetizing roasting of siderite- hematite iron ore using a synergistic $\mathrm{CO}-$ H2 mixture. J Iron Steel Res Int. 2019;27:12-21. http://dx.doi. org/10.1007/s42243-019-00242-w.

23. Zhao Q, Xue J, Chen W. Upgrading of iron concentrate by fluidized-bedmagnetizing roasting of siderite to magnetite in CO-H2-N2 atmosphere. Trans Indian Inst Met. 2019;72:138191. http://dx.doi.org/10.1007/s12666-019-01636-w.

24. Wu F, Cao Z, Wang S, Zhong H. Phase transformation of iron in limonite ore by microwave roasting with addition of alkali lignin and its effects on magnetic separation. J Alloys Compd. 2017;722:651-61, https://doi.org/10.1016/j.jallcom.2017.06.142.

25. Wu F, Cao Z, Wang S, Zhong H. Novel and green metallurgical technique of comprehensive utilization of refractory limonite ores. J Clean Prod. 2018;171:831-43. http://dx.doi.org/10.1016/j. jclepro.2017.09.198.

26. Sunil SR, Rayapudi V, Dhawan N. Recovery of iron values from discarded iron ore slimes. Min Metall Explor. 2019;37:287-95. https://doi.org/10.1007/s42461-019-00119-2.

27. Roy SK, Nayak D, Dash N, Dhawan N, Rath SS. Microwaveassisted reduction roasting-magnetic separation studies of two mineralogically different low-grade iron ores. Int J Miner Metall Mater. 2020;27:1449-61. http://dx.doi.org/10.1007/s12613-0201992-5.

28. Samouhos M, Taxiarchou M, Tsakiridis PE, Potiriadis K. Greek "redmud" residue: a study ofmicrowave reductive roasting followed by magnetic separation for a metallic iron recovery process. J Hazard Mater. 2013;254-255:193-205. http://dx.doi. org/10.1016/j.jhazmat.2013.03.059. 